\title{
Avanços recentes na pesquisa em fixação biológica de nitrogênio no Brasil*
}

\section{JOHANNA DÖBEREINER}

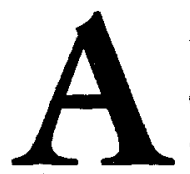

biologia do solo oferece inúmeras alternativas para 0 desenvolvimento de novas biotecnologias que visam substituir sistemas agrícolas tradicionais baseados no crescente uso de fertilizantes químicos e agrotóxicos. Devido ao alto custo dos fertilizantes nitrogenados $(70 \%$ dos custos dos fertilizantes), a fixação biológica de nitrogênio que permite o uso, pelas plantas, do $\mathrm{N}_{2}$ molecular da atmosfera, é o processo mais estudado na biologia do solo, e os desenvolvimentos da biotecnologia moderna em muito contribuíram para os progressos recentes neste campo. A agricultura tropical não só é sujeita à erosão e, portanto, menos apropriada para agrossistemas baseados em uso intensivo de fertilizantes; ela ainda oferece umidade e temperaturas ótimas durante todo $o$ ano para a atividade microbiológica.

$\mathrm{Na}$ presente conferência, os avanços biotecnológicos mais recentes na pesquisa relacionada com fixação biológica de nitrogênio no Brasil (FBN) e as suas implicaçóes com a agricultura tropical serão discutidos.

\section{Fixação de $\mathbf{N}_{2}$ em leguminosas}

As leguminosas possuem o mecanismo simbiótico mais sofisticado e eficiente entre as associaçóes de plantas superiores com bactérias fixadoras de $\mathrm{N}_{2}$ e as leguminosas de grão e forrageiras têm papel importante na agricultura tropical. O sucesso da soja no Brasil se deve a um programa de melhoramento direcionado à obtenção de cultivares com alta produção sem adubação nitrogenada e ao desenvolvimento em paralelo de inoculantes contendo rizóbios adaptados às condiçóes e solos brasileiros. $O$ avanço da soja para os cerrados se deve, além da identificação e solução dos problemas de fertilidade, principalmente à obtençáo de inoculantes novos capazes de competir com a microflora de um ecossistema perturbado após a conversão dos cerrados em terras de cultura. A adubação e calagem destes solos resulta numa multiplicaçáo indiscriminada de actinomicetos produtores de antibióticos (COELHO e DROZDOWICZ, 1979) e a sobrevivência dos rizóbios inoculados nestes solos depende da resistência à streptomicina e vários outros antibióticos (SCOTTI et al., 1982).

* Conferencia proferida pela professora Johanna Döbereiner, da Universidade Rural do Rio de Janeiro, no IEA em 16 de março de 1989. 
QUADRO 1.

EFEITO DA ESTIRPE DE BRADTRHIZOBIUM JAPONICUM NA NODULAÇĀO, NO N UREIDEO, NA SEIVA E NO TNDICE DE COEHEITA DE N EM SOJA CRESCIDA EM VASOS COLOCADOS AO AR LIVRE (NEVES at al., 1985).

\begin{tabular}{|c|c|c|c|c|}
\hline Estirpe & $\begin{array}{l}\text { Peso seco } \\
\text { dos nódulos } \\
\text { (mg por planta) }\end{array}$ & $\begin{array}{l}\begin{array}{l}\text { Eficiência } \\
\text { relativa }\end{array} \\
\left(1-\left(-\frac{\mathrm{H}_{2}}{\mathrm{C} 2 \mathrm{H}_{4}}\right)\right.\end{array}$ & $\begin{array}{c}\text { N ureídeo } \\
(\mathrm{xg} N \mathrm{~cm}-3)\end{array}$ & $\begin{array}{c}\text { Indice de } \\
\text { colheita de } N \\
\text { (N na semente) x100 } \\
N \text { total }\end{array}$ \\
\hline $\begin{array}{l}29 W \\
\text { DF } 395 \\
\text { SMlb } \\
965 \\
\text { CB } 1809 \\
\text { DF } 383\end{array}$ & $\begin{array}{l}230 \mathrm{a} a \\
307 \mathrm{a} \\
233 \mathrm{a} \\
97 \mathrm{~b} \\
83 \mathrm{~b} \\
92 \mathrm{~b}\end{array}$ & $\begin{array}{l}0.74 b \\
0.41 c \\
0.30 c \\
0.97 a \\
0.98 a \\
0.94 a\end{array}$ & $\begin{array}{l}323.3 b \\
194.3 c \\
209.5 c \\
580.0 a \\
627.1 a \\
439.5 b\end{array}$ & $\begin{array}{l}58.9 \mathrm{~b} \\
52.1 \mathrm{~b} \\
55.9 \mathrm{~b} \\
68.8 \mathrm{a} \\
69.0 \mathrm{a} \\
67.7 \mathrm{a}\end{array}$ \\
\hline
\end{tabular}

(a) Valores seguidos pela mesma letra näo săo diferentes com $p=0.05$ (Dunkan's teste).

Estudos mais recentes revelaram ainda que há rizóbios de soja muito mais eficientes que os atualmente usados nos cerrados e que transferem proporçáo maior do $\mathrm{N}$ fixado aos gráos (NEVES et al., 1985). Estas estirpes possuem um mecanismo de reciclamento do $\mathrm{H}_{2}$ liberado durante o processo da reduçáo do $\mathrm{N}_{2}\left(\mathrm{HUP}^{+}\right)$que de forma ainda desconhecida é relacionado com a incorporaçáo do $\mathrm{N}$ fixado em forma de ureídeos, que por sua vez transportam o $\mathrm{N}$ diretamente aos grãos (quadro 1), havendo menor perda com a caída das folhas. A inoculação com estas estirpes de rizóbios, em solos onde não foi plantada soja anteriormente com outros inoculantes, pode proporcionar aumentos de produçăo de gráos na ordem de $40 \%$ (quadro 2). Estas estirpes, entretanto, são pouco competitivas e ainda năo foi possível estabelecê-las em campos de cerrado onde já foi plantada soja inoculada anteriormente.

Inter-relaçóes semelhantes entre eficiência nodular, HUP, transporte de $\mathrm{N}$ em forma de ureídeos $\mathrm{e}$ índice de colheita foram também observadas em feijăo (HUNGRIA e NEVES, 1986, NEVES e

QUADRO 2.

EFEITOS DA ESTIRPE DE RHIZOBTUM

NA FIXAÇÃO DE NITROGÊNIO DE SOJA CRESCIDA NO CAMPO (NEVES et al., 1985).

\begin{tabular}{|c|c|c|c|c|}
\hline Estirpe & $\begin{array}{l}\text { N2 fixado } \\
(\mathrm{kg} \mathrm{N} \text { ha-1) }\end{array}$ & $\begin{array}{l}\text { Eficiência nodular } \\
\text { (mg N2 fix.g-1 nod.) }\end{array}$ & $\begin{array}{l}\text { Produçăo } \\
\text { kg ha-1 }\end{array}$ & $\begin{array}{c}\text { Indice de colheita } \\
\text { de } \mathrm{Na}\end{array}$ \\
\hline $\begin{array}{l}29 W \\
\text { DF } 395 \\
\text { SM1b } \\
965 \\
\text { CB } 1809 \\
\text { DF 383 } \\
\text { Control }\end{array}$ & $\begin{array}{c}343 b \\
214 b \\
204 c \\
278 a \\
239 b \\
242 b \\
0\end{array}$ & $\begin{array}{c}426 c \\
543 b \\
491 b \\
899 a \\
1005 a \\
851 a \\
-\end{array}$ & $\begin{array}{l}1863 c \\
1768 c d \\
1398 d e \\
2898 a \\
2682 a \\
2284 b \\
948 f\end{array}$ & $\begin{array}{l}60.1 \mathrm{~b} \\
61.1 \mathrm{~b} \\
56.0 \mathrm{~b} \\
86.5 \mathrm{a} \\
82.2 \mathrm{a} \\
82.0 \mathrm{a} \\
49.1 \mathrm{bc}\end{array}$ \\
\hline
\end{tabular}


HUNGRIA, 1987), onde, em vez de dois grupos distintos de eficiência nodular, etc., parece ter variaçōes contínuas influenciadas também pelo genótipo da planta (figura 1). A fixaçăo de $\mathrm{N}_{2} \mathrm{em}$ feijáo tem problemas adicionais causados pela instabilidade genética das estirpes de rizóbios isoladas desta cultura, que é causada pelo rearranjamento freqüente do DNA (MARTINEZ et al., 1988), que ainda é acelerado sob temperaturas elevadas $\left(35\right.$ a $\left.40^{\circ} \mathrm{C}\right)$ que frequientemente ocorrem em nossos solos. Estes autores observaram dois grupos de rizóbios capazes de nodular o feijão, o grupo I, que é específico para Pbaseolus vulgaris e que é instável em relação a sua performance simbiótica, enquanto o grupo II, além do feijão, nodula várias leguminosas, principalmente arbóreas, e mostra características dos rizóbios destas espécies que são mutto mais estáveis, nodulando e fixando $\mathrm{N}_{2}$ com até $40^{\circ} \mathrm{C}$ (CUNHA e FRANCO, com. pess.). A seleção entre mais que 100 estirpes de rizóbio que nodulam leguminosas arbóreas resultou em um grupo de 11 que são capazes de nodular o feijăo, metade dos quais fixando nitrogênio normalmente em regime de $8 \mathrm{~h} /$ dia de $40^{\circ} \mathrm{C}$ (quadro 3) (HUNGRIA e FRANCO, 1988). Estes resultados recentes podem vir a solucionar o problema da fixação de $\mathrm{N}_{2} \mathrm{em}$ feijáo até então sem soluçáo à vista. Como no caso da soja, no entanto ainda há necessidade de adaptação destas estirpes às condiçóes de solos ácidos $\mathrm{e}$ fazê-las mais competitivas com os rizóbios que ocorrem naturalmente em nossos solos.

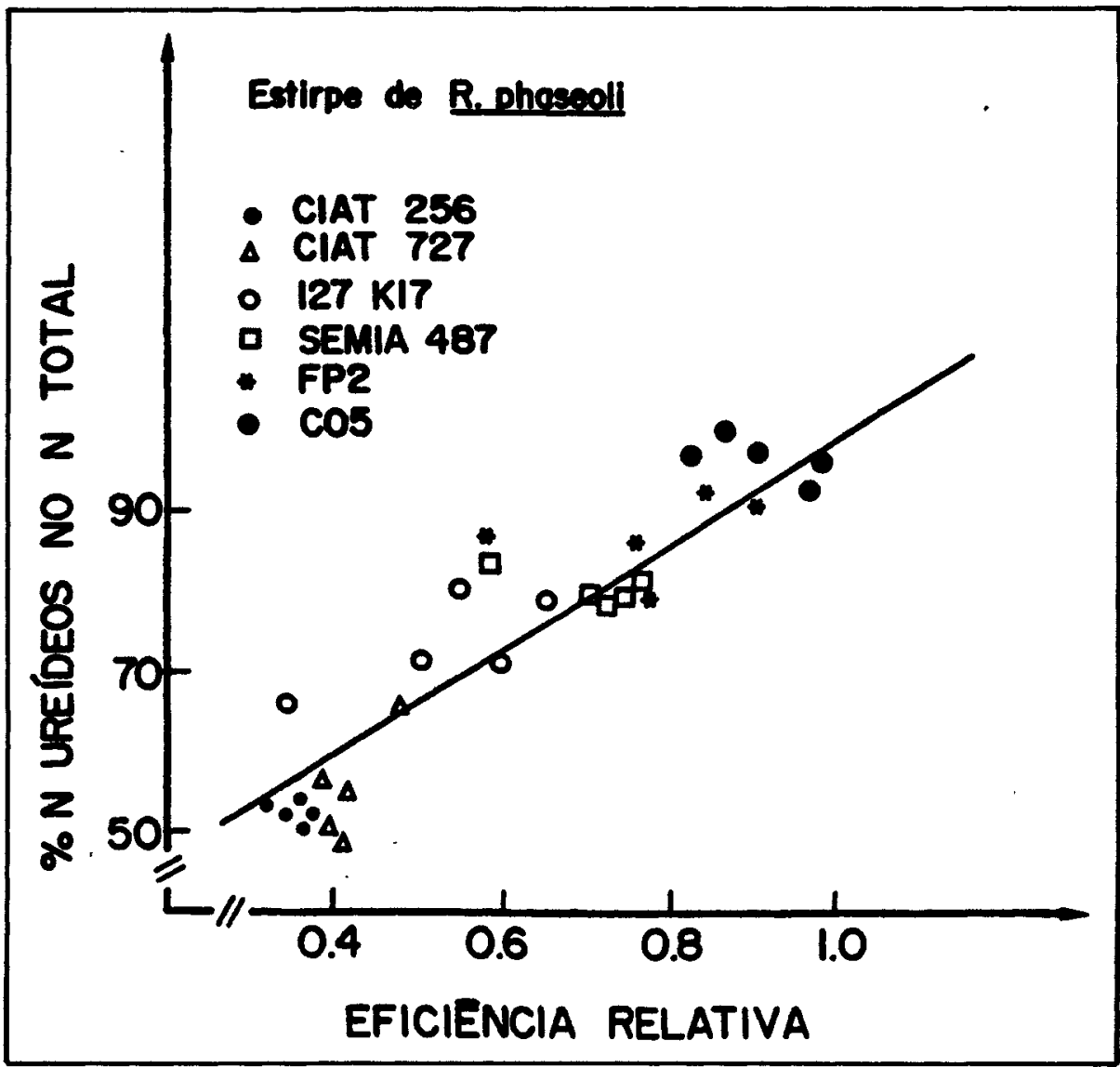

Figura 1. Correlafaco entre a eficiência relatipa $R E=1-\left(C_{2} H_{4} \times 100\right)$ e a concentraģáo de $N$ ureddeo na seiva ( $r=0.903$ ) (Hungria e Neves, 1986). 
QUADRO 3.

NODULAÇĀO E FIXAÇĀO DE N2 SOB TEMPERATURAS DO SOLO EXCESSIVAS (8H POR DIA A $40^{\circ} \mathrm{C}$ ) DE FEIJÄO INOCULADO COM RIZOBTUM SP. ISOLADO DE LEGUMINOSAS ARBÓREAS (HUNGRIA e FRANCO, 1988).

\begin{tabular}{l|c|c|c}
\hline Origem da estirpe & No $^{\circ}$ estirpe & $\begin{array}{c}\mathbf{N}^{\circ} \text { nódulos } \\
\text { por planta }\end{array}$ & $\begin{array}{c}\text { N total } \\
\text { (mg por planta) }\end{array}$ \\
\hline Gliricidia sp. & $\mathrm{Br} 8801$ & $8 \mathrm{c}$ & $15 \mathrm{~d}$ \\
& 8802 & $20 \mathrm{~cd}$ & $22 \mathrm{~cd}$ \\
Leucaena sp. & 8803 & $12 \mathrm{c}$ & $14 \mathrm{~d}$ \\
& $\mathrm{Br} 814$ & $46 \mathrm{~b}$ & $4 \mathrm{ab}$ \\
Lonchocarpus sp. & 816 & $40 \mathrm{bc}$ & $41 \mathrm{ab}$ \\
& 817 & $68 \mathrm{a}$ & $52 \mathrm{a}$ \\
& $\mathrm{Br} 6009$ & $14 \mathrm{de}$ & $28 \mathrm{c}$ \\
Phaseolus vulgaris & 5010 & $60 \mathrm{ab}$ & $48 \mathrm{ab}$ \\
P. vulgaris + 90 mg N/planta & 6011 & $20 \mathrm{cde}$ & $22 \mathrm{~cd}$ \\
\hline
\end{tabular}

Fixação de nitrogênio em cereais e cana-de-açúcar:

A extensão da FBN aos cereais e à cana-de-açúcar representa um dos maiores desafios da pesquisa em biologia do solo, já que estas culturas representam a maior parcela nas culturas plantadas em nosso meio, usando mais que $90 \%$ dos fertilizantes nitrogenados vendidos no país. Gramíneas incluindo cereais e cana-de-açúcar não formam nódulos com bactérias fixadoras de $\mathrm{N}_{2}$ como as leguminosas. Mas nos últimos 15 anos, foram descobertas 10 novas espécies de bactérias fixadoras de $\mathrm{N}_{2}$ que vivem numa associação menos perfeita nas raízes das gramíneas, 7 delas descobertas no Brasil (quadro 4). Estas bactérias todas sáo microaeróbias quando dependentes da FBN, isto é, somente fixam $\mathrm{N}_{2}$ quando náo há acúmulo de oxigênio em torno delas. A chave para o descobrimento deste grupo novo de bactérias foi o uso de meios de cultura semi-sólidos onde, atraídas pela quimotactia, as bactérias se movem para a região no meio onde a taxa de difusão de $\mathrm{O}_{2}$ é menor ou igual à taxa de respiraçáo das bactérias.

Todas estas bactérias, com excessão do Acetobacter diazotrophicus, em regióes tropicais e subtropicais ocorrem em números entre $10^{3} \mathrm{e} 10^{6} \mathrm{~g}^{-1}$ no solo e, geralmente, em números maiores ainda na superfície de raízes de cereais e gramíneas forrageiras (MAGALHÃES et al., 1983, BALDANI et al., 1986). Foram ainda isoladas do interior das raízes (raízes tratadas com desinfectantes) e em alguns casos também dos colmos (quadro 4). A. halopraeferans é comum na superfície de raízes, mas náo no interior de capim "Kallar", importante forrageira para solos áridos salinos no Paquistáo (REINHOLD et al., 1987). Esta espécie apresenta uma adaptação marcante às condiçóes áridas, tendo, como temperatura ótima para crescimento e fixação de $\mathrm{N}_{2}, 41^{\circ} \mathrm{C}$. Esta bactéria não foi encontrada $\mathrm{em}$ solos salinos do Rio de Janeiro ou em raízes de várias outras gramíneas colhidas na região semi-árida do Nordeste. Mas estirpes de $A$. brasilense, isoladas de raízes destas gramíneas, mostram adaptação considerável a temperaturas elevadas e concentraçóes de sal quando comparadas às estirpes isoladas na regiáo Centro-Sul do país (figura 2). 


\section{QUADRO 4.}

COMPARAÇÃO DE NOVAS BACTÉRIAS FIXADORAS DE N2 QUE OCORREM EM ASSOĆIAÇĀO COM RAfZES. (BALDANI et al., 1986, BARRAQUIO et al., 1983, CAVALCANTE e DÖBERENNER, 1988, REINHOLD tt al., 1988, SELDN, et al., 1984, TARRAND et al., $1978 \mathrm{e}$ WATANABE et al., 1987).

\begin{tabular}{|c|c|c|c|c|c|c|c|}
\hline & 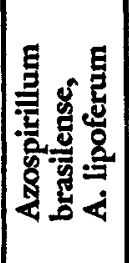 & 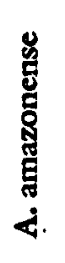 & 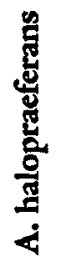 & 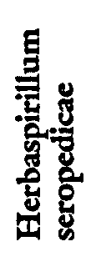 & 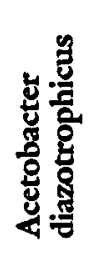 & 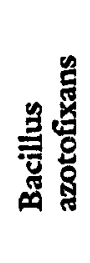 & 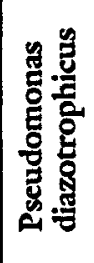 \\
\hline Crescimento sob ar & + & + & + & + & + & + & + \\
\hline $\begin{array}{l}\text { Crescimento com } \mathrm{N}_{2} \\
\text { como única fonte de } \mathrm{N}\end{array}$ & + & + & + & + & + & + & - \\
\hline $\begin{array}{l}\text { Fixação de N2 não- } \\
\text { afetada por } 10 \mathrm{mMN03}\end{array}$ & - & - & - & - & + & + & \\
\hline Usa sacarose & - & + & - & - & + & \pm & - \\
\hline Temperatura ótima (C) & 35 & 35 & 41 & 35 & 30 & 32 & 30 \\
\hline $\begin{array}{l}\text { Isolada do interior } \\
\text { de raízes }\end{array}$ & + & + & - & + & + & + & + \\
\hline Isolada de colmos & + & + & - & - & + & - & + \\
\hline
\end{tabular}
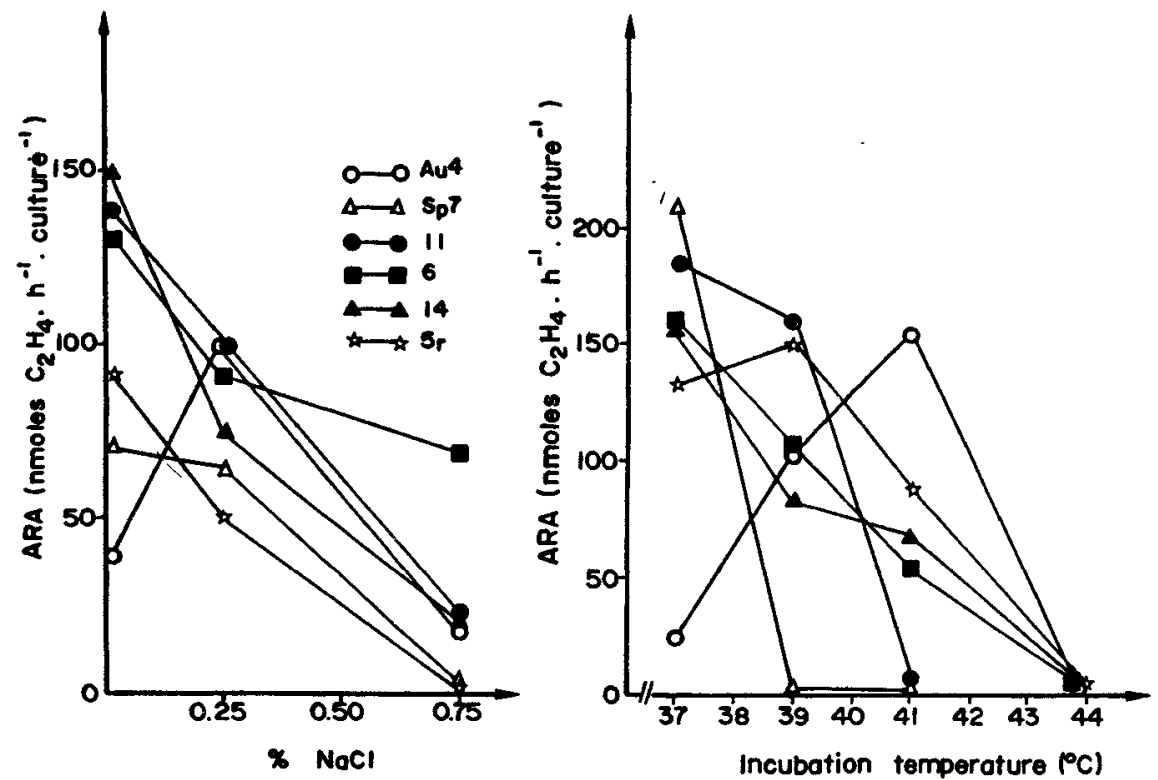

Figura 2. Tolerdncia no sal e temperaturas excesivas de Azospirillum balopraeferans (AwA), $A$. brasilense (Sp 7 ) isolado do solo e trés especies de $A$. brasilense $(11,6,14)$ e wana de $A$. lipoferum (5r) isoladas de ralizes de gramineas forrageiras no Nordeste (Reinhold, 1988). 
Como no caso das leguminosas, o efeito da inoculaçáo de cereaís com estas bactérias depende do estabelecimento delas sob condiçōes de campo. Um exemplo do efeito da inoculação de sorgo é apresentado no quadro 5. Os resultados mais consistentes até agora foram obtidos com trigo no sul do Brasil (BALDANI et al., 1987). O quadro 6 dá um exemplo de um experimento onde Azospirillum brasilense Sp7 isolado do solo náo se estabéleceu nas raízes do trigo, enquanto $A$. amazonense $\mathrm{XTr}$, isolado de raízes lavadas de trigo, foi intermediário e $A$. brasilense $S_{p} 245$, isolado de raízes esterilizadas, se estabeleceu bem e teve o efeito mais pronunciado no crescimento do trigo. Este efeito da estirpe Sp 245, entretanto, não pode ser atribuído à fixaçăo de $\mathrm{N}_{2}$ mas sim a um efeito da bactéria na eficiência do uso do fertilizante nitrogenado (BODDEY et al., 1986). Isto foi confirmado em cultura monoxênica com mutantes nitrato-redutase negativas desta estirpe (FERREIRA et al., 1987), indicando papel importante da nitrato-redutase da bactéria na associaçáo destas bactérias com a planta. Por outro lado, duas das bactérias citadás no quadro 4 não possuem nitrato-redutase, o que lhes permite de fixar $\mathrm{N}_{2}$, mesmo na presença de altas concentraçóes de nitrato no solo ou na planta, fato que favorece a complementaçáo da fertilizaçáo nitrogenada com FBN.

A bactéria nova mais recente, o Acetobacter diazotrophicus, apresenta características extraordinárias que provêm de seu habitat, as raízes e colmos do cana-de-açúcar (CAVALCANTE e DÖBEREINER, 1988, GILLIS et al.; 1988). A bactéria foi isolada em grandes números de cana de Pernambuco, Alagoas, Minas Gerais e Săo Paulo e não foi encontrada no solo mesmo no canavial, nem em doze espécies de ervas daninhas colhidas entre e dentro das fileiras da cana (REIS et al., 1988). Isto indica que náo se trata de bactéria do solo, mas sim de bactéria cujo babitat é a planta e que sua propagaçáo se dá com o plantio dos toletes da cana. Como outras bactérias acéticas, ela é um pequeno bastonete Gram negativo, aeróbio que cresce melhor com altas concentrações de açúcar (10\%) em meio ácido, mostrando

\section{QUADRO 5.}

INOCULAÇĀO DE SORGO CRESCIDO NO CAMPO COM BACTÉRIAS FIXADORAS DE N2 (PEREIRA et al., 1988).

\begin{tabular}{|c|c|c|c|c|c|}
\hline \multirow[b]{2}{*}{ Inoculante } & \multicolumn{3}{|c|}{ Estabelecimento das estirpes inoculadas ${ }^{2}$} & \multirow{2}{*}{$\begin{array}{l}\text { Peso seco } \\
\text { da planta } \\
\mathbf{g}^{\mathbf{l}} \mathbf{- 1}\end{array}$} & \multirow{2}{*}{$\begin{array}{l}N \text { total } \\
\text { na espiga } \\
\text { mg pl-1 }\end{array}$} \\
\hline & $\begin{array}{l}\text { Superfície } \\
\text { da raiz }\end{array}$ & $\begin{array}{l}\text { Interior } \\
\text { da raiz }\end{array}$ & Colmo & & \\
\hline Testemunha & $0(12) b$ & $0(50) b$ & $11(22) \mathrm{b}$ & $15.7 \mathbf{b}$ & $41 c$ \\
\hline Test. $+75 \mathrm{~kg} \mathrm{~N} / \mathrm{ha}-1$ & & - & - & $19.6 \mathrm{ab}$ & $98 \mathbf{a}$ \\
\hline $\begin{array}{l}\text { Azospirillum } \\
\text { lipoferum S82 }\end{array}$ & 80 & 75 & 75 & $21.5 a$ & $68 \mathrm{ab}$ \\
\hline $\begin{array}{l}\text { Azospirillum } \\
\text { amazonense S91 }\end{array}$ & 50 & 29 & 30 & 19.6ab & 78ab \\
\hline $\begin{array}{l}\text { Herbaspirillum } \\
\text { seropedicae H25 }\end{array}$ & 0 & 0 & $\mathbf{0}$ & $15.6 b$ & $57 \mathrm{bc}$ \\
\hline
\end{tabular}

a Percentagem dos frascos de diluigăo mais alta (NMP) contendo a estirpe inoculada; controles foram testados para todos os inoculantes. 
QUADRO 6.

INOCULAÇÃO DE TRIGO COM AZOSPIRILUM SPP MARCADO COM RESISTÊNCIA A ANTIBIÓTICOS (BALDANI et. al., 1986, BODDEY ct. al., 1986).

\begin{tabular}{c|c|c|c|c}
\hline \multirow{2}{*}{ Estirpe } & \multicolumn{2}{|c|}{$\%$ estirpe inoculada a } & \multicolumn{1}{c|}{$\begin{array}{c}\text { total } \\
\text { na planta }\end{array}$} & $\begin{array}{c}\text { Produção } \\
\text { de grăos }\end{array}$ \\
\cline { 2 - 5 } & $\begin{array}{c}\text { Superfícic } \\
\text { raízes }\end{array}$ & $\begin{array}{c}\text { Interior } \\
\text { raízes }\end{array}$ & \multicolumn{2}{c}{ g/parcela } \\
Testemunha & 0 & 0 & $0.66 \mathrm{c}$ & $23.2 \mathrm{c}$ \\
A. brasilense & & & & \\
Sp 7 & 50 & 0 & $0.87 \mathrm{c}$ & $27.0 \mathrm{c}$ \\
Sp 246 & 94 & 27 & $1.29 \mathrm{~b}$ & $35.1 \mathrm{~b}$ \\
Sp 245 & 100 & 67 & $1.57 \mathrm{a}$ & $41.5 \mathrm{a}$ \\
A. amazonense & 56 & 11 & $1.26 \mathrm{~b}$ & $31.9 \mathrm{~b}$ \\
\hline
\end{tabular}

a Percentagem dos frascos de diluiçäo mais altos (NMP) contendo a estirpe inoculada.

fixação de $\mathrm{N}_{2}$ e crescimento sem outra fonte de $\mathrm{N}$ em $\mathrm{pH}$ abaixo de 3 durante vários dias (TEIXEIRA et al.,1987). Etanol é completamente oxidado a $\mathrm{CO}_{2}$ e $\mathrm{H}_{2} \mathrm{O}$, formando o brilho nacreo típico deAcetobacter em placas com $\mathrm{CaCO}_{3}$.

O potencial de fixaçáo de $\mathrm{N}_{2}$ em gramíneas pôde ser melhor avaliado pela diluiçăo isotópica de $15 \mathrm{~N}$ aplicado ao solo em forma de uréia e cuja relaçắo com $14 \mathrm{~N}$ na planta, proveniente do $\mathrm{N}_{2}$ gasoso, permite calcular a contribuição da $\mathrm{FBN}$, a nutriçăo nitrogenada da planta. Experimentos deste tipo mostraram fixaçáo de $\mathrm{N}_{2}$ de 20 a $40 \%$ do $\mathrm{N}$ total incorporado em certas cultivares de capim-colonião (Panicum maximum) e espécies de Bracchiaria. Os dados mais promissores foram

\section{QUADRO 7.}

FIXAÇÃO DE N2 EM DIFERENTES GENÓTIPOS DE CANA-DE-AÇÚCAR ESTIMADA EM UM TANQUE DE 80 CM DE PROFUNDIDADE PELO N TOTAL ACUMULADO E PELA DILUIÇÃO ISOTÓPICA DE 15N (URQUIAGA, S., BODDEY, R.M. e DÖBERREINER, J., EM PREPARAÇÂO).

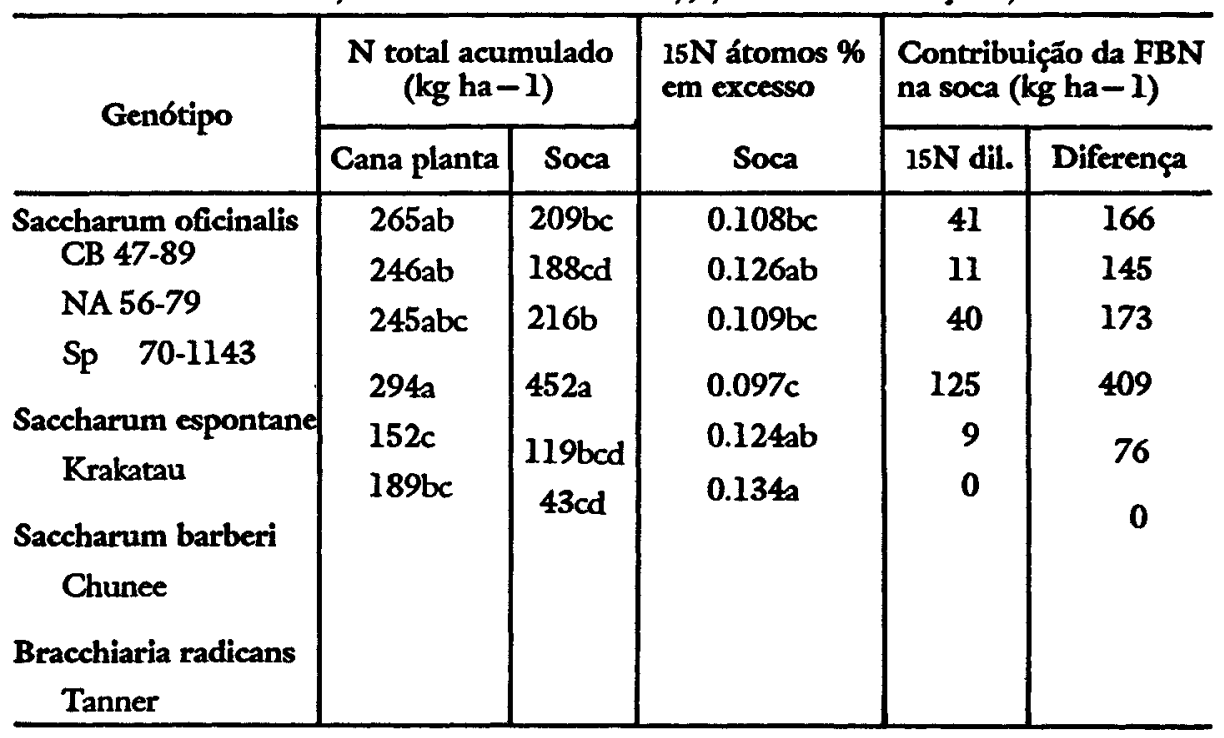


recentemente obtidos com a cana-de-açúcar, usando a mesma metodologia e comparando variedades de cana cultivadas em um tanque grande preenchido com solo marcado com $15 \mathrm{~N}$ (quadro 7). Resultados semelhantes foram também obtidos num experimento de vasos grandes (50 litros), onde os cálculos pela diluição isotópica ainda foram confirmados por balanços de $\mathrm{N}$ e onde a variedade de cana CB 47-89 obteve 70\% do nitrogênio através da fixação biológica (LIMA et al., 1987), enquanto outras variedades como a NA 56-79 recebeu pouco $\mathrm{N}$ da FBN. Estas diferenças entre genótipos de gramíneas em relação a FBN mostram um grande potencial para a sua melhor exploração através de melhoramento vegetal.

Os resultados recentes com cana-de-açúcar podem vir a, parcialmente, solucionar o problema dos subsídios do álcool, já que a substituição da fertilização nitrogenada nesta cultura reduzirá os insumos sem perda de produtividade. Além disso, em função dos elevados custos também energéticos dos adubos nitrogenados, a sua substituição contribuirá para o aumento do balanço energético.

Bibliografia

BALDANI, J.I., BALDANI, V.L.D., SELDIN, L. e DÖBEREINER, J. 1986. Characterization of Herbaspirillum seropedicae gen. nov., sp. nov., a root-associated nitrogen-fixing bacterium. Int. J. Syst. Bacteriol.36:86-93.

BALDANI, V.L.D., ALVAREZ, M.A.B., BALDANI, J.I. e DÖBEREINER, J. 1986. Establishment of inoculated Azospirillum spp. in the rhizosphere and in roots of field grown wheat and sorghum. Plant \& Soil 90:35-45.

BALDANI, V.L.D., BALDANI, J.I. e DÖBEREINER, J. 1987. Inoculation of field grown wheat with Azospirillum spp. in Brazil. Biol. Fert. Soils 4:37-40.

BARRAQUIO, W.L., LADHA, J.K. e WATANABE, I. 1983. Isolation and identification of N2-fixing Pseudomonas associated with wetland rice. Can. J. Microbiol. 29(8): 867-873.

BODDEY, R.M., BALDANI, V.L.D., BALDANI, J.I. e DÖBEREINER, J. 1986. Effect of inoculation of Azospirillum spp on the nitrogen assimilation of field grown wheat. Plant of Soil 95:109-121.

CAVALCANTE, V.A. e DÖBEREINER, J. 1988. A new acid-tolerant nitrogen-fixing bacterium associated with sugar cane. Plant \& Soil 108:23-31.

COELHO, R.R.R. e DROZDOWICZ, A. 1979. The occurrence of actinomycetes in a cerrado soil in Brazil. Revuc de Ecologie ct Biologic du Sol 15:459-73.

DÖBEREINER, J. 1966. Azotobacter paspali sp.n., uma bactéria fixadora de nitrogênio na rizosfera de Paspalum. Pesq. Agropec. Bras. 1:357-365.

FERREIRA, M.C.B., FERNANDES, M.S. e DÖBERENNER, J. 1987. Role of Azospirillum nitrate reductase in nitrate assimilation by wheat plants. Biol. Fert. Soils 4: 47-53.

GILLIS, M., JANSSENS, D., HOSTE, J., KERSTSERS, J., DÖBEREINER, J. e DE LEY, J. 1988. Genotypic and phenotypic characterization of new, nitrogen-fixing Acetobrater sp. associated with sugar cane. In: International Comgress on Nitrogen Fỉxation, 7, Köln, 1988. Abstracts... Köln (Cologne), University of Cologne/Max Planck Institute for Plant Breeding. Session 8-17. n.p.

HUNGRIA, M. e FRANCO, A.A. 1988. Obtenção de estirpes de Rbizobium para inoculação do feijoeiro em condiçốes de temperaturas elevadas. In: Comgresso e Feira $\mathrm{Na}$ cional de Biotecnologia, 1, Rio de Janeiro. Programa e resumos... Rio de Janeiro, Secretaria de Ciência e Tecnologia do Estado do Rio de Janeiro. Area focal, 4: Biotecnologia Vegetal e Agricola. p. 15.

HUNGRIA, M. e NEVES, M.C.P. 1986. Interação entre cultivares de Phaseolus vulgaris e estirpes de Rhizobium na fixação e transporte de nitrogênio. Pesq. Agropec. Bras. 21:127-140. 
LIMA, E., BODDEY, R.M. e DÖBEREINER, J. 1987. Quantification of biological nitrogen fixation associated with sugar cane using on $15 \mathrm{~N}$ aided nitrogen balance. Soil Biol. Biochem. 19:165-170.

MAGALHĀES, F.M.M., BALDANI, J.I., SOUTO, S.M., KUYKENDALL, J.R. e DÖBEREINER, J. 1983. A new acid-tolerant Azospirillum species. An. Acad. Bras. Ciln.55:417-430.

MARTINEZ, E., FLORES, E., BROM, S., ROMERO, D., DAVILA, G. e PALACIOS, R. 1988. Rhizobium phaseoli a molecular genetics view. Plant o Soill 08:179-184.

NEVES, M.C.P., DIDONET, A.D., DUQUE, F.F. e DÖBEREINER, J. 1985. Rhizobium strain effects on nitrogen transport and distribution in soybean. J. Exp. Bot. 36:1179-1192.

NEVES, M.C.P. e HUNGRIA, M. 1987. The physiology of nitrogen fixation in tropical grain legumes. CRC Critical Rep. Plant Sci.6:267-321.

PEREIRA, A.R., CAVALCANTE, V.A., BALDANI, J.I. e DÖBEREINER, J. 1988. Field inoculation of sorghum and rice with Azospirillum spp. and Herbaspirillum seropedicae. Plant \& Soil (in press).

REINHOLD, B.J., HUREK, T., BALDANI, J.I. e DÖBERELNER, J. 1988. Temperature and salt tolerance of Azospirillewe spp. from salt-affected soils in Brazil. In: Klingmüller, W., ed. Azospirillum IV: Genetics, physiology, ecology. Berlin, Springer Verlag. p. 234-41.

REINHOLD, B.J., HUREK, T., FENDRIK, I., POT, B., GILLIS, M., KERSTSERS, K., THIELEMANS, D. e DE LEY, J. 1987. Azospirillum jalopracferans sp. nop., a nitrogen fixing organcism associated with roots of Kallar grass (Leptochloa fusca $L$. Kunth). Int. J. Syst. Bacteriol.37:43-51.

REIS, V.M., LAZARINI, A.C. e DÖBERENNER, J. 1988. Ocorrência de nova bactéria fixadora de $\mathrm{N}_{2}$ em raízes e colmos de cana-de-açúcar. In: Congresso e Fcira Nacional de Biotecnologia, 1, Rio de Janeiro. Programa e resumos... Rio de Janeiro, SCTRJ/MCI/ABRABI, 1988. n.p.

SCOTTI, M.R.M.M.L., SA, N.M.H., VARGAS, M.A.T. e DÖBEREINER, J. 1982. Streptomycin resistance of Rhizobium isolates from Brazilian Cerrados. An. Acad. Brasil. Cilnc., 54(4):733-738.

SELDN, L., VAN ELSAS, J. D. e PENIDO, E.G.C. 1984. Bacillus azotofixans sp. nov. a nitrogen-fixing specie from Brazilian soils and grass roots. Int. J. Syst. Bucteriol. 34:451-456.

TARRAND, J.J., KRIEG, N.R. e DÖBEREINER, J. 1978. A taxonomic study of the Spirillum lipoferum group with description of a new genus, Azospirillum gen. nov. and two species, Azospirillum lipoferum (Beijerinck) comb. nov. and Azospirillum brasilense sp. nov. Can. J. Mecrobiol.24:967-980.

TEIXEIRA, K.R.S., STEPHAN, M.P. e DÖBEREINER, J. 1987. Physiological studies of Saccharobacter nitrocuptasssa new acid tolerant $\mathrm{N}_{2}$ fixing bacterium. In: Interniational Symposizem on Nitrogen Fixation with Non-Legnemes, 4. Rio de Janeiro, EMBRAPA. p. 149.

WATANABE, I., SO.R, LADHA, J.K., FUIMUUA-KATAYAMA, Y. e KURAISHI, H. 1987. A new nitrogen-fixing species of pseudomonad: Pseudomonas diazotrophicus sp. nov. isolated from the root of wethand rice. Can. J. Micrabiol.33(8):670-678.

Johanna Döbereiner, pesquisadora da Empresa Brasileira de Pesquisa Agropecuária (Embrapa) e conferencista do mês de março/1989 do IEA. 